Note

\author{
Correspondence \\ Yoon-Hoh Kook \\ yhkook@plaza.snu.ac.kr
}

\section{Legionella busanensis sp. nov., isolated from cooling tower water in Korea}

\author{
Mi-Yeoun Park, ${ }^{1}$ Kwan Soo Ko, ${ }^{2}$ Hae Kyung Lee, ${ }^{1}$ Man-Suk Park ${ }^{1}$ \\ and Yoon-Hoh Kook ${ }^{2}$ \\ ${ }^{1}$ Laboratory of Rickettsial and Zoonotic Disease, Department of Microbiology, Korean National
Institute of Health, Seoul 122-701, Korea \\ ${ }^{2}$ Department of Microbiology and Cancer Research Institute, Institute of Endemic Diseases, \\ SNUMRC, Seoul National University College of Medicine and Clinical Research Institute, \\ Seoul National University Hospital, Seoul 110-799, Korea
}

\begin{abstract}
Three Legionella-like micro-organisms, isolated from cooling tower water of a building in Busan, Korea, were characterized by a variety of biochemical and molecular phylogenetic tests. Analyses of whole-cell fatty acids and results of biochemical tests revealed that these three isolates are distinct from previously described Legionella species. Furthermore, results of comparative analyses of $16 \mathrm{~S}$ rDNA (1476-1488 bp), mip (408 bp) and rpoB (300 bp) sequences also confirmed that these strains represent a novel species within the genus Legionella. The 16S rDNA sequences of the three Korean isolates had similarities of less than $95 \cdot 8 \%$ to other Legionella species. Phylogenetic trees formed by analysis of the $16 \mathrm{~S} \mathrm{rRNA}, r p o B$ and mip genes revealed that the isolates formed a distinct cluster within the genus Legionella. Based on the evaluated phenotypic and phylogenetic characteristics, it is proposed that these Korean isolates from water be classified as a novel species, Legionella busanensis sp. nov.; the type strain is strain $\mathrm{K} 951^{\top}$ $\left(=\right.$ KCTC $12084^{\top}=$ ATCC BAA $\left.-518^{\top}\right)$.
\end{abstract}

The genus Legionella was first identified in 1977 following an epidemic of acute pneumonia in Philadelphia (Fraser et al., 1977). At the time of writing, 47 species have been described (Euzéby, 1997; Lo Presti et al., 2001), including four Legionella-like amoebal pathogens (Hookey et al., 1996; Adeleke et al., 2001). Twenty-one species are pathogenic to humans (Winn, 1999). Morphology and biochemical traits are so alike between species or so atypical that they are of no use in the differentiation of species within the genus Legionella (Winn, 1999). Thus, the use of fatty acid analysis and molecular tools, such as DNA-DNA relatedness and 16S rRNA gene sequencing, have recently gained prominence for the identification of novel species (Benson et al., 1996; Lo Presti et al., 1999).

Three Legionella-like organisms (strains K9951 ${ }^{\mathrm{T}}$, K9952 and K9953) were isolated in 1999 from the water of cooling towers in Busan, Korea, by the Korea National Institute of Health (KNIH). On the basis of their cultural and staining

Published online ahead of print on 14 June 2002 as DOI 10.1099/ ijs.0.02268-0.

The GenBank accession numbers for the $16 \mathrm{~S}$ rDNA, rpoB and mip

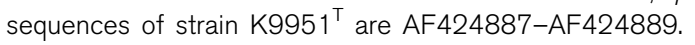

An rpoB-based dendrogram including a wider selection of Legionella type strains is available as supplementary material in IJSEM Online (http://ijs.sgmjournals.org/). characteristics, they were tentatively identified as members of Legionella. They grew for 3-4 days at $35 \pm 1{ }^{\circ} \mathrm{C}$ in the presence of $2 \cdot 5 \% \mathrm{CO}_{2}$ on buffered charcoal/yeast extract (BCYE) agar, but not in the absence of L-cysteine. The organisms were Gram-negative and were observed to form cut-glass colonies on BCYE- $\alpha$ agar (Winn, 1999) under the dissecting microscope, both of which are characteristics of Legionella. Buffer and cysteine were respectively omitted for the determination of autofluorescence and requirement for cysteine (Benson et al., 1996). Biochemical tests for gelatinase, urease, catalase, oxidase, peroxidase and $\beta$-lactamase activities, as well as hippurate hydrolysis, nitrate reduction, autofluorescence and browning of tyrosinesupplemented agar were performed as described previously (Fox \& Brown, 1989; Hebert, 1981; Orrison et al., 1981; Pine et al., 1984; Weaver \& Feeley, 1979). The three strains were tested with commercially available antisera (Denka Seiken) and antisera prepared in the KNIH laboratory against the type strains of 13 Legionella species including 25 serogroups (Legionella pneumophila serogroups 1-15, Legionella dumoffii, Legionella micdadei, Legionella bozemanii, Legionella gormanii, Legionella anisa, Legionella feeleii serogroup 2, Legionella longbeachae serogroups 1 and 2, Legionella parisiensis, Legionella rubrilucens, Legionella spiritensis, Legionella wadsworthii and Legionella jordanis) by the slide-agglutination test (Benson et al., 1996). 
The three strains were cultivated in BCYE broth for $48 \mathrm{~h}$ at $35 \pm 1{ }^{\circ} \mathrm{C}$ and negatively stained with $2 \%$ uranyl acetate to identify flagella by TEM $(\times 15000$; JEOL, JEM-1010). Analysis of cellular fatty acid composition was performed using a Hewlett Packard 6890A GC and the MIDI aerobe method (Chem Station ver. 4.02) at MicroID, Daejeon, Korea. The cellular fatty acid profiles were compared with those of Diogo et al. (1999). The G+C contents of DNA from the three strains were determined spectrophotometrically by the thermal denaturation method (Marmur \& Doty, 1962).

Genomic DNA was prepared from the three Korean isolates using the bead beater-phenol extraction method (Kim et al., 1999). The $16 \mathrm{~S}$ rDNA $(\sim 1.5 \mathrm{~kb})$ was amplified by PCR using primers p246 and pH (Eckloff et al., 1994). The purified PCR product was sequenced directly using an Applied Biosystems model 377 automated sequencer and a BigDye Terminator cycle sequencing kit (Perkin-Elmer Applied Biosystems). Primers pL259 (5'-GGCGACGATCG GTAGCTGGT-3') and pL632 (5'-GTGGAATTTCCGGTG TAGCGG-3') were used as internal primers for sequencing. For the amplification of partial $r p o B$ and mip DNAs, primers RL1 (5'-GATGATATCGATCAYCTDGG-3')/RL2 (5' -TTC VGGCGTTTCAATNGGAC-3') and ML1 (5'-GATAAGTT GTCTTATAGCATTGG-3')/ML2 (5'-TCTGTCCATCCTG GGATAACTTG-3'), respectively, were used. The determined nucleotide sequences of 16S rDNA (1476-1488 bp), rpoB DNA [300 bp; 1407-1436 bp in Nielson et al. (2000)] and mip DNA [408 bp; 832-1239 bp in Bangsborg et al. (1991)] were submitted to GenBank and used for phylogenetic analyses. The $16 \mathrm{~S}$ rDNA and mip sequences of other Legionella species and Coxiella burnetii retrieved from GenBank were also used. Phylogenetic trees were constructed according to the neighbour-joining method with the PAUP program (Swofford, 1999). The robustness of the groupings was estimated by bootstrap analysis (1000 replications).

The three isolates were thought to belong to the genus Legionella in view of their Gram-negative staining and requirement for L-cysteine for growth at $35^{\circ} \mathrm{C}$. Therefore, their biochemical characteristics were compared with those of previously described Legionella species. The three strains possessed a single subpolar flagellum. Biochemical tests for gelatinase, hippurate hydrolysis and oxidase were positive. However, tests were negative for $\beta$-lactamase and browning of tyrosine-supplemented agar. The results of biochemical tests such as gelatinase, hippurate, oxidase and $\beta$-lactamase activities indicated that these strains did not belong to any currently described Legionella species (Hookey et al., 1996). No autofluorescence was observed when colonies of the three isolates were exposed to UV light. They did not react with any of the 25 antisera tested.

The three Korean strains contained unsaturated fatty acids, predominantly $16: 1 \omega 7 c(43 \cdot 58-46 \cdot 62 \%)$, followed by i-16: $0(16 \cdot 47-20 \cdot 07 \%)$ and $16: 0(8 \cdot 60-10 \cdot 13 \%)$. Other fatty acids also detected were: $15: 1 \omega 6 c(4 \cdot 25-5 \cdot 96 \%) ; 17: 0$ $(2 \cdot 52-3 \cdot 25 \%) ; 18: 0(2 \cdot 91-3 \cdot 16 \%)$; i-14:0 (2.65-2.98\%); i-18:0 (1.65-3.05\%); ai-15:0 (1.58-2.18\%); $15: 0(1 \cdot 32-$ $2 \cdot 37 \%)$; ai- $17: 0(1 \cdot 30-1 \cdot 38 \%) ; 14: 1 \omega 5 c(1 \cdot 06-1 \cdot 60 \%)$; and 20:0 (0-1.25\%). The fatty acid composition also demonstrated that these strains did not correspond to any previously described Legionella species (Diogo et al., 1999). According to Hookey et al. (1996) and Diogo et al. (1999), Legionella adelaidensis, L. feeleii, Legionella geestiana, Legionella moravica, Legionella quateirensis, Legionella quinlivanii, Legionella santicrucis, Legionella worsleiensis, Legionella sp. Montbeliard A1 and Legionella sp. Greoux $11 \mathrm{D} 13$ contain predominantly $16: 1 \omega 7 c$. However, all of these species, with the exception of Greoux 11D13, had a $16: 1 \omega 7 c$ content of below $35 \%$. In the strain Greoux 11D13, the compositions of the other fatty acids were significantly different from those of the three Korean strains (Diogo et al., 1999), thus supporting the distinction of these three strains from other Legionella species.

The sequence similarities of three different genes determined for each of the three Korean isolates were more than $99 \%$. Sequence similarities of $16 \mathrm{~S}$ rDNA between $\mathrm{K}^{2} 951^{\mathrm{T}}$ and other species of Legionella ranged from 91.5 to $95 \cdot 8 \%$, the highest degree of relatedness being for Legionella birminghamensis. Sequence similarities of $r p o B$ and mip between $\mathrm{K}_{9951}{ }^{\mathrm{T}}$ and other Legionella species respectively ranged from $76 \cdot 3$ (L. geestiana) to $85 \cdot 0 \%$ (Legionella hackeliae) and from $64 \cdot 7$ (L. worsleiensis) to $76 \cdot 5 \%$ (L. feeleii). All phylogenetic trees inferred from the three gene sequences indicated that the three isolates were grouped into a distinct cluster. This cluster was supported robustly with bootstrap values of $100 \%$, although the relationships with other Legionella species showed minor differences depending on the gene (Fig. 1). It has been proposed that members of one genus that share less than $97 \% 16 \mathrm{~S}$ rDNA sequence similarity should be regarded as separate species (Stackebrandt \& Goebel, 1994). In this study, nearly complete 16S rDNA sequences (14761488 bp) of strains $\mathrm{K} 9951^{\mathrm{T}}$, K9952 and $\mathrm{K} 9953$ all demonstrated less than $95 \cdot 8 \%$ sequence similarity with other species in the genus Legionella. Coupled with the $16 \mathrm{~S}$ rDNA sequences, the sequences for $r p o B$ and mip, which have been suggested as alternative targets for bacterial phylogeny and identification (Mollet et al., 1997; Ratcliff et al., 1998; Kim et al., 1999; Dahllöf et al., 2000; Ko et al., 2002), also showed considerable divergence from other members of Legionella. The G+C contents of strains K9951 ${ }^{\mathrm{T}}$, K9952 and K9953 were respectively $37 \cdot 5,36 \cdot 1$ and $35 \cdot 9 \mathrm{~mol} \%$.

Thus, in light of the complementary nature of all the results described above, of biochemical tests, cellular fatty acid composition and molecular genetic studies, a novel species of the genus Legionella, Legionella busanensis sp. nov., is proposed for the Korean isolates.

\section{Description of Legionella busanensis sp. nov.}

Legionella busanensis (bu.san.en'sis. N.L. adj. busanensis from Busan in Korea, where the type strain was isolated). 


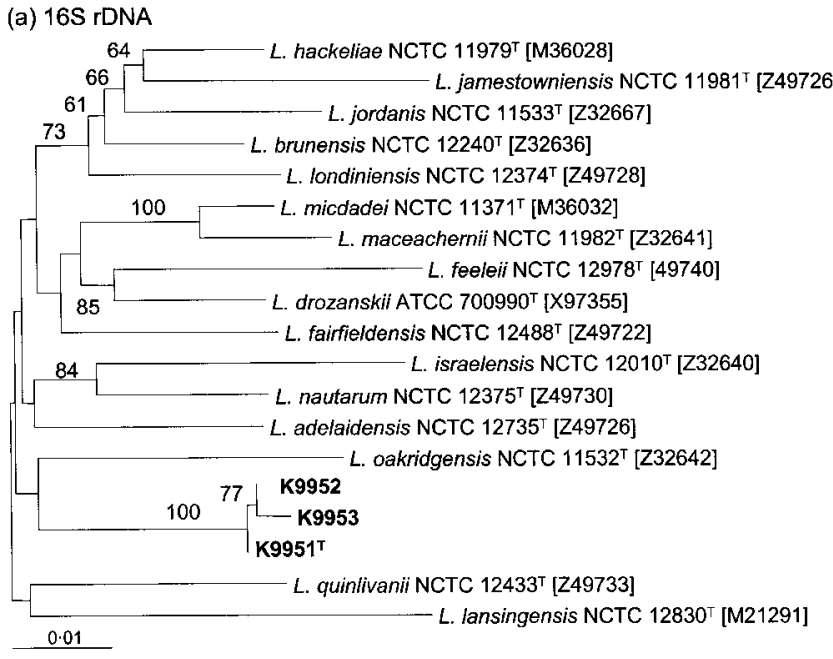

Fig. 1. Phylogenetic relationships of $L$. busanensis sp. nov. and reference Legionella species. The trees were inferred by the neighbour-joining method. Numbers at branching nodes are percentages of 1000 bootstrap replications; only values greater than $50 \%$ are indicated. (a) Tree constructed on the basis of $16 \mathrm{~S}$ rDNA sequences. Coxiella burnetii was used as an outgroup, as shown in (b). (b) rpoB phylogeny of 15 Legionella type strains and the three strains of $L$. busanensis sp. nov. A dendrogram including 38 species is available as supplementary material in IJSEM Online (http://ijs.sgmjournals.org/). (c) mip phylogeny of Legionella species including the three strains of $L$. busanensis $\mathrm{sp}$. nov. Abbreviation: gsp., genomospecies. Bars, 1 (a) or 5 (b, c) substitutions per $100 \mathrm{nt}$. (b) $r p \circ B$

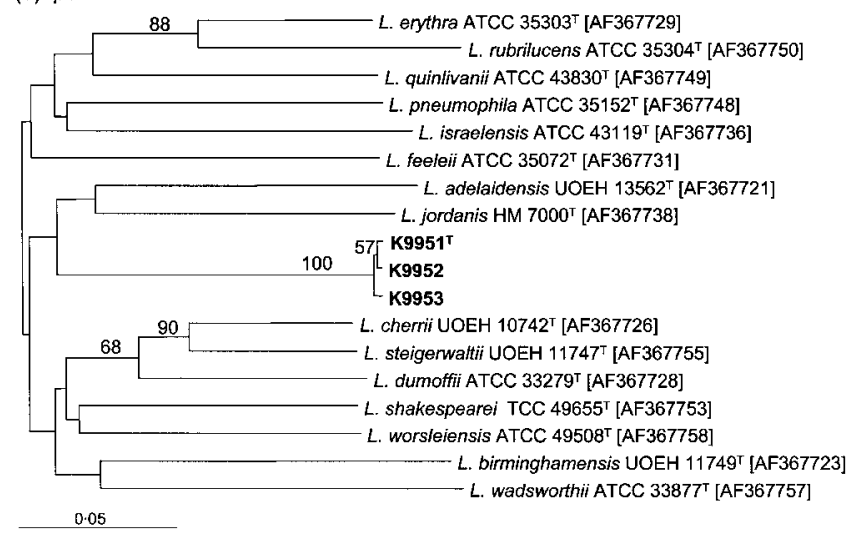

(c) mip

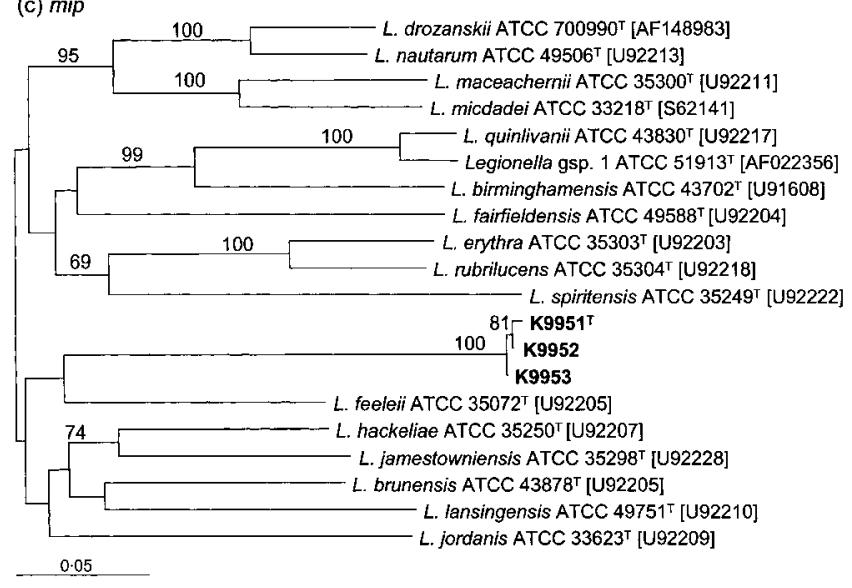

Gram-negative rod with a single subpolar flagellum. Grows on BCYE agar, but not on media without L-cysteine. Positive for gelatinase activity, catalase activity, hydrolysis of hippurate, oxidase activity and hydrolysis of starch; negative for urease activity, peroxidase activity, reduction of nitrate to nitrite and browning of tyrosine-supplemented agar. No autofluorescent reaction. Contains the unsaturated fatty acids $16: 1 \omega 7 c, i-16: 0$ and $16: 0$ as the major fatty acid components. All three strains of this species were isolated from water samples taken from cooling towers in Busan, Korea. The type strain is strain $\mathrm{K}^{2} 951^{\mathrm{T}}$ $\left(=\right.$ KCTC $12084^{\mathrm{T}}=$ ATCC BAA- $\left.518^{\mathrm{T}}\right)$. It has a G+C content of $37.5 \mathrm{~mol} \%$.

\section{Acknowledgements}

M.-Y. P. and K. S. K. contributed equally to this work as joint first authors. We thank Professor J. Chun (School of Biological Sciences, $\mathrm{SNU}$ ) for his helpful comments in the preparation of this manuscript. We also thank Drs Barry S. Fields, Robert F. Benson and Ellen Brown (National Center for Infectious Diseases, CDC, USA) and Miss E. H. Park (Busan Metropolitan City Institute of Health and Environment) for supplying us with reference strains and isolates. This work was supported by a grant from the Korea Health 21 R\&D Project, Ministry of Health and Welfare, Republic of Korea (01-PJ10-PG6-01GM03-0002), by Grant 2001 from SNU College of Medicine and the Hospital Research fund, in part by the BK21 project for Medicine, Dentistry and Pharmacy, and by Grant 2001 from Korean National Institute of Health.

\section{References}

Adeleke, A. A., Fields, B. S., Benson, R. F. \& 8 other authors (2001). Legionella drozanskii sp. nov., Legionella rowbothamii sp. nov. and Legionella fallonii sp. nov.: three unusual new Legionella species. Int J Syst Evol Microbiol 51, 1151-1160.

Bangsborg, J. M., Cianciotto, N. P. \& Hindersson, P. (1991). Nucleotide sequence analysis of the Legionella micdadei mip gene, encoding a 30-kilodalton analog of the Legionella pneumophila Mip protein. Infect Immun 59, 3836-3840.

Benson, R. F., Thacker, W. L., Daneshvar, M. I. \& Brenner, D. J. (1996). Legionella waltersii sp. nov. and an unnamed Legionella genomospecies isolated from water in Australia. Int J Syst Bacteriol 46, 631-634.

Dahllöf, I., Baillie, H. \& Kjelleberg, S. (2000). rpoB-based microbial community analysis avoids limitations inherent in $16 \mathrm{~S}$ rDNA gene intraspecies heterogeneity. Appl Environ Microbiol 66, 3376-3380.

Diogo, A., Verissimo, A., Nobre, M. F. \& da Costa, M. S. (1999). Usefulness of fatty acid composition for differentiation of Legionella species. J Clin Microbiol 37, 2248-2254. 
Eckloff, B., Podzorski, R. P., Kline, B., \& Cockerill, F. R., III (1994). A comparison of $16 \mathrm{~S}$ ribosomal DNA sequences from five isolates of Helicobacter pylori. Int J Syst Bacteriol 44, 320-323.

Euzéby, J. P. (1997). List of Bacterial Names with Standing in Nomenclature: a folder available on the Internet. Int J Syst Bacteriol 47, 590-592.

Fox, K. F. \& Brown, A. (1989). Application of numerical systematics to the phenotypic differentiation of Legionellae. J Clin Microbiol 17, 1952-1955.

Fraser, D. W., Tsai, T. R., Orenstein, W. \& 9 other authors (1977). Legionnaires' disease: description of an epidemic of pneumonia. $N$ Engl J Med 297, 1189-1197.

Hebert, G. A. (1981). Hippurate hydrolysis by Legionella pneumophila. J Clin Microbiol 13, 240-242.

Hookey, J. V., Saunders, N. A., Fry, N. K., Birtles, R. J. \& Harrison, T. G. (1996). Phylogeny of Legionellaceae based on small-subunit ribosomal DNA sequences and proposal of Legionella lytica comb. nov. for Legionella-like amoebal pathogens. Int J Syst Bacteriol 46, 526-531.

Kim, B.-J., Lee, S.-H., Lyu, M.-A. \& 7 other authors (1999). Identification of mycobacterial species by comparative sequence analysis of the RNA polymerase gene (rpoB). J Clin Microbiol 37, 1714-1720.

Ko, K. S., Lee, H. K., Park, M.-Y., Park, M.-S., Lee, K. H., Woo, S.-Y., Yun, Y.-J. \& Kook, Y.-H. (2002). Population genetic structure of Legionella pneumophila inferred from RNA polymerase gene (rpoB) and DotA gene $(\operatorname{dot} A)$ sequences. $J$ Bacteriol 184, 2123-2130.

Lo Presti, F., Riffard, S., Meugnier, H. \& 8 other authors (1999). Legionella taurinensis sp. nov., a new species antigenically similar to Legionella spiritensis. Int J Syst Bacteriol 49, 397-403.

Lo Presti, F., Riffard, S., Meugnier, H. \& 9 other authors (2001). Legionella gresilensis sp. nov. and Legionella beliardensis sp. nov., isolated from water in France. Int J Syst Evol Microbiol 51, 19491957.
Marmur, J. \& Doty, P. (1962). Determination of the base composition of deoxyribonucleic acid from its thermal denaturation temperature. J Mol Biol 4, 109-118.

Mollet, C., Drancourt, M. \& Raoult, D. (1997). $r p o B$ sequence analysis as a novel basis for bacterial identification. Mol Microbiol 26, 1005-1011.

Nielsen, K., Hindersson, P., Høiby, N. \& Bangsborg, J. M. (2000). Sequencing of the $r p o B$ gene in Legionella pneumophila and characterization of mutations associated with rifampin resistance in the Legionellaceae. Antimicrob Agents Chemother 44, 2679-2683.

Orrison, L. H., Cherry, W. B., Fliermans, C. B., Dees, S. B., McDougal, L. K. \& Dodd, D. J. (1981). Characteristics of environmental isolates of Legionella pneumophila. Appl Environ Microbiol 42, 109-115.

Pine, L., Hoffman, P. S., Malcom, G. B., Benson, R. F. \& Gorman, G. W. (1984). Whole-cell peroxidase test for identification of Legionella pneumophila. J Clin Microbiol 19, 286-290.

Ratcliff, R. M., Lanser, J. A., Manning, P. A. \& Heuzenroeder, M. W. (1998). Sequence-based classification scheme for the genus Legionella targeting the mip gene. J Clin Microbiol 36, 1560-1567.

Stackebrandt, E. \& Goebel, B. M. (1994). Taxonomic note: a place for DNA-DNA reassociation and 16S rRNA sequence analysis in the present species definition in bacteriology. Int J Syst Bacteriol 44, 846-849.

Swofford, D. L. (1999). PAUP*: phylogenetic analysis using parsimony ( ${ }^{*}$ and other methods), version 4 . Sunderland, MA: Sinauer Associates.

Weaver, R. E. \& Feeley, J. C. (1979). Cultural and biochemical characterization of Legionnaires' disease bacterium. In Legionnaires', the Disease, the Bacterium, and Methodology, pp. 20-25. Edited by G. L. Jones \& G. A. Hebert. Atlanta, GA: Centers for Disease Control. Winn, W. C. (1999). Legionella. In Manual of Clinical Microbiology, 7th edn, pp. 572-582. Edited by P. R. Murray. Washington, DC: American Society for Microbiology. 